\title{
Family and fertility: does kin help influence women's fertility, and how does this vary worldwide?
}

\author{
Rebecca Sear ${ }^{1 \star}$
}

\begin{abstract}
Despite the tendency of some academic disciplines to assume that the nuclear family is normative, the family takes a number of different forms cross-culturally. Regardless of family form, family members typically cooperate in raising children. Intergenerational help (from grandparents to parents and children), for example, is a cross-cultural universal. Such cooperation means that the availability of kin may be one salient factor in deciding whether and when to have children. Here I consider the evidence for whether the availability of kin does influence fertility, and whether these relationships vary cross-culturally. I find evidence from middle and lower income populations that the presence of kin does increase fertility, and that these relationships are plausibly driven by cooperation between family members. In higher income contexts, associations between kin and fertility are mixed, and appear particularly sensitive to how kin availability and support is measured. There is some evidence that certain measures of support from kin (such as emotional support or help with childcare) increases the likelihood of subsequent births, but kin support is not always positively associated with fertility. Family matters for fertility, then, though these relationships may be complex and context-specific. Policy needs to take this diversity into account, and should not focus exclusively on the nuclear family model, nor neglect the roles other family members play in reproductive decisions.
\end{abstract}

Keywords: family, fertility, kin, cross-cultural, comparative research, grandparents, support

DOI 10.1515/pophzn-2017-0006

Received: 8 March 2017, Accepted: 22 January 2018

\section{Introduction}

In the UK, many social science and popular news articles on the family ${ }^{1}$ open by noting the substantial changes in the family which have occurred over the last few decades. Such opening statements often seem to imply that the family form typical of the-mid-20 ${ }^{\text {th }}$ century Western middle classes - the nuclear family, male breadwinner, female homemaker model - is the

1 In this article, I focus on families which include children, because I'm interested in the reproductive decision-making process, although I'm aware that many families do not include children. This should not be read as attaching any kind of value judgement to those families or households which do not include children normative family form, so that shifts away from this model require special explanation. The changes in family structure and relationships which happened between the mid and late $20^{\text {th }}$ century have even been described as 'family decline' (Popenoe 1993). But taking a cross-cultural and historical perspective on the family shows how misguided this idealisation of the nuclear family is (Sear 2016). The family takes many forms worldwide (Goody 1976). While longterm relationships between women and men are typically the context in which children are raised across cultures, these relationships are not always monogamous nor lifelong (Coontz 2004; Walker et al. 2011). Women's and men's roles in the household are also rarely so rigidly separated as in the male

^Corresponding author: rebecca.sear@lshtm.ac.uk

${ }^{1}$ London School of Hygiene and Tropical Medicine 
breadwinner-female homemaker model (Kaplan and Lancaster 2003). More commonly, women and men contribute to both the household economy and raising children - though there is often a sexual division of labour such that women and men have complementary, rather than identical, roles in both productive and domestic labour; nor do women and men always make equal contributions to both spheres (Kaplan et al. 2009; Hewlett 2000). Nuclear families are also rarely autonomous (or 'isolated'): other family members often coreside with adult women and men, and invariably contribute to raising children in some way, even if not coresident (Hill and Kaplan 1999). It is the importance of the extended family which this paper will focus on.

The extended family has by no means been entirely neglected in social science research. There is a particularly rich seam of research on kin in anthropology (Shenk and Mattison 2011), and in some branches of demography (Caldwell 1978; Ruggles 1986; Laslett 1988; Burch and Gendell 1970). Researchers focusing on contemporary European and Europeanorigin populations have tended to emphasise the nuclear family, however, perhaps partly because of the assumption that the isolated, male-breadwinner family has been common in Western Europe for some centuries. While there is recognition in recent years of the importance of intergenerational relationships in European populations, this is often justified by the assumption that intergenerational relationships are only now becoming particularly important, as populations age and lifespans are extended (Dunifon 2013; Bengtson 2001). These assumptions about the historical predominance of the isolated nuclear family in Europe, and the novelty of important intergenerational relationships, are now being challenged on several fronts (Basu 2017; Crompton, Lewis, and Lyonette 2007; Fortunato 2017). This paper, too, questions whether this model is ever a particularly useful model of the human family. Instead, I use a theoretical framework not from social science but from evolutionary biology, which assumes that intergenerational relationships, and other relationships with extended family members, are of great importancein all human societies. This framework has important policy implications, since research informed by it has found considerable evidence that family members have significant influences on each other's health, wellbeing and fertility.

Evolutionary social scientists are interested in extended families, and how they influence demographic and health outcomes, because kin selection theory states that genetic relatives will have a vested interest in improving each other's fitness, in evolutionary terms; for example, by improving each other's health, wellbeing and reproductive success (Hamilton 1964) ${ }^{2}$. Of particular relevance to this paper is the related hypothesis that humans are 'cooperative breeders', that is, mothers require help to raise children because of the high costs of raising children in our species (Hrdy 2009; Hrdy 2005; Reiches et al. 2009). This help is most likely to come from relatives, because of kin selection (though not exclusively). Our children have long periods of childhood dependency, and also come along relatively rapidly, because of our short inter-birth intervals, compared to closely related ape species. This means that mothers must care for multiple dependent children, at different developmental stages, simultaneously; a burden of care they likely can only manage by using the help of fathers, grandparents, older children, other relatives and sometimes non-relatives. If the cooperative breeding hypothesis is correct, then the 'typical human family' is one in which there is considerable cooperation between family members, within and outside the nuclear family, in supporting one another to raise children.

\section{Potential policy implications of the cooperative breeding framework}

The cooperative breeding framework has implications for contemporary societies, not least in that policy which assumes the nuclear family, male breadwinnerfemale homemaker model is the norm is unlikely to suit individuals' evolved preferences. If we have evolved to raise children in the context of cooperative networks of kin then policies which emphasise only the nuclear family may have adverse consequences, in that a lack of suitable support from outside the nuclear family may adversely affect the health and wellbeing of both children and parents, and reduce fertility rates (Hrdy 2009). There is now substantial evidence that the presence of supportive family members other than

2 More precisely, Hamilton's Rule states that kin will help one another when the costs of helping are outweighed by the benefits of helping, weighted by the coefficient of relatedness (the probability that a gene will be shared between two individuals: which is 0.5 for parents and children or siblings; 0.25 for grandparents and grandchildren, etc). 
parents, particularly grandmothers, improves child health in high mortality populations (Aubel, Toure, and Diagne 2004; Sear and Mace 2008; Hawkes, O’Connell, and Blurton Jones 1989; Bezner Kerr et al. 2008; Douglass and McGadney-Douglass 2008). Even in societies where children's physical health needs are largely met, the mother-centred childrearing idealised in the nuclear family model (Robert A LeVine 2014; Otto and Keller 2014; Vicedo 2013) may reduce children's ability to learn social skills and successfully develop relationships with multiple individuals beyond the mother (Hrdy 2009). It may also affect their ability to pick up childrearing skills themselves by practising on their younger siblings (Sear 2016); older siblings are likely to be one valuable resource mothers have typically had to help them raise younger children, since sibling childcare is common in high fertility societies worldwide (Kramer 2005). If contemporary child-rearing practices fail to recognise the importance of multiple caregivers for developing interpersonal skills, then empathy and the quest Hrdy (2009) cautions that 'Compassion and the quest for emotional connection will fade away as surely as sight in cave-dwelling fish'.

Parents' health and wellbeing may also suffer, if they are expected to raise children with little help from outside the nuclear family. Postnatal depression in mothers, for example, is a significant public health concern in industrialised populations (Wisner, Chambers, and Sit 2006), and has been proposed to result from an evolutionary 'mismatch' between our evolved preferences for a supported childrearing environment, and contemporary practices which isolate mothers away from necessary support (Hahn-Holbrook and Haselton 2014); it has recently been shown to reduce the likelihood of subsequent childbearing (Myers, Burger, and Johns 2016), illustrating the potential consequences of such practices for fertility. Kin support also allows women to fulfil preferences for combining work and family life (Hakim 2003): grandparental childcare increases women's labour force participation quite substantially in the UK (Kanji 2017). Fathers' health and wellbeing, too, may suffer from the expectations of being able to single-handedly support a family, a heavy burden which has not been expected of most fathers throughout human history (Gray and Crittenden 2014; Silverstein, Auerbach, and Levant 2002; Durette, Marrs, and Gray 2011). While the benefits of receiving support are easy to understand, there is even some evidence that the health and wellbeing of those providing support (specifically, the grandparental generation) is improved if they are involved in caring for others (Hilbrand, Coall, Gerstorf, et al. 2017; Hilbrand, Coall, Meyer, et al. 2017), suggesting the benefits of family support may be felt by all the family.

The cooperative breeding framework also has implications for fertility. If parents have to bear the high costs of raising children without sufficient support, then family size will be low. This has been proposed to be one factor influencing the demographic transition from high to low fertility in Western Europe: the increase in geographic mobility associated with industrialisation resulted in dispersed kin networks, reducing support for childbearing (Turke 1989; Newson et al. 2005). Low fertility will then perpetuate itself, not just because small families provide fewer avenues for supporting parents, but also perhaps by diminishing parenting knowledge and skills, which may reduce the likelihood of having children, or having many children. The childrearing periods of successive generations may be separated by years or decades in low fertility societies, unlike the overlapping or almost overlapping childbearing periods in high fertility societies. This will contribute to a lack of practice or observation of raising children that parents in societies which idealise the nuclear families have about raising children, as childrearing increasingly goes on behind closed doors. The importance of the extended family therefore extends to a range of policy-relevant areas.

This broad brush description of human families is not meant to dismiss the considerable variability across human societies in the nature of family relationships. Marriage, residence, inheritance and migration patterns vary so that individuals may have greater or lesser contact with different family members. For example, though evidence suggests that throughout most of human history, residence patterns were very fluid (Hill et al. 2011), many modern societies have norms or practices which mean that women are more likely to live with, or close by, either their husband's kin (patrilocality) or their own (matrilocality). Residence patterns also vary in that extended families typically live together in some societies, though this may take a variety of different forms, for example: 'stem' families where grandparents live with one adult child, spouse and grandchildren; or 'joint' families where several adult siblings may live together with spouses, children and grandparents (Ruggles 2010). In other societies, households consisting only of nuclear families are more common. The cooperative breeding framework 
suggests that women get help from others flexibly, so that while help for childrearing is universal, exactly who helps women raise children may vary between societies, between individual women, and over time, depending on who is willing and available to help, and may also include help from individuals who are not related to the mother or child (Courtney L Meehan, Helfrecht, and Quinlan 2014; Hill and Hurtado 2009; Mace and Sear 2005).

This variability includes variation in the role of fathers (Hrdy 2000b; Hrdy 2008). Polygyny (one man with several female partners) is common and polyandry (one woman with several male partners) not uncommon in cultures across the world, and divorce rates are variable. Even long-term relationships between mothers and fathers don't necessarily involve coresidence, though they may involve close relationships between fathers and children (Gray and Brown 2015; Flinn 1992; Mattison, Scelza, and Blumenfield 2014). So, although fathers very often support women's reproduction, not all men invest heavily in their children, and exactly what they do for their partners and children can vary between men and societies. In contrast to the male breadwinner model, this may include direct childcare or other domestic labour, alongside providing food and other resources, and housing or protection (Gettler 2016).

Even maternal relationships with children are not uniform across societies (Hrdy 2000a). Despite an assumption of universal and unwavering 'mother love', there is substantial evidence that maternal investment is contingent on a range of factors, and may be withdrawn if that investment may harm the mother's own health or that of her other children (Hrdy and Sieff 2015). We are one of the few primate species where infanticide by mothers is known to occur occasionally (Daly and Wilson 1984). It is perhaps not a coincidence that another exception are callitrichids (marmosets and tamarins); small south American monkeys who are also among the few other mammals that practice cooperative breeding (Hrdy 2016). When raising children is as costly as it is in our species (and callitrichids, who frequently give birth to twins), then mothers may be better off withdrawing investment in a child with few chances of survival, and waiting until a better opportunity to have a child presents itself. Infanticide is a rare event, of course. For the vast majority of children, mothers do invest intensively in their children in early life, but even this investment wanes as children grow and as mothers delegate childrearing to other individuals. The sharing of childcare for babies is certainly not uncommon crossculturally (Ivey 2000), and once children are weaned they may spend their time predominantly in the care of individuals other than the mother, even sometimes being fostered out, so that their care becomes entirely the responsibility of others. Fostering has in fact been described as a form of 'dispersed cooperative breeding' (Scelza and Silk 2014).

Policy-makers therefore need to recognise the diversity of family forms, and that diversity exists in relationships between mothers, fathers, children and other individuals. Children can be raised successfully in a wide range of family arrangements. An exclusive focus on the nuclear family, where mothers are primarily responsible for childcare, and fathers are the only other contributors to the family, risks being an inappropriate and unhelpful model for many (perhaps all) families, especially if families which clearly 'deviate' from this norm are demonised. Such a focus may even decrease health, wellbeing and fertility for most (perhaps all) families, since the rarity of the isolated nuclear family worldwide suggests it may not provide an optimal environment in which to raise children.

\section{Do kin influence fertility, and why?}

For the rest of this paper I focus on the question of whether and how kin influence fertility, drawing particularly on my recent work in this area, funded by the European Research Council (ERC). Fertility rates have declined almost worldwide in relatively recent history, so that global fertility is now only about 2.5 children per woman ${ }^{3}$. The fertility of many high income populations is considerably lower, and below replacement level (the level needed to maintain population size). This has led to concerns both about how to cope with aging populations (Harper 2000), and why women are not fulfilling their fertility intentions, which are typically higher than achieved fertility, in these populations: the gap between women's intended and achieved fertility has been described as an 'unmet need for children' (Harknett and Hartnett 2014). Some lower income populations have quite different policy concerns surrounding childbearing, including both how to

3 http://www.prb.org/Publications/Datasheets/2016/2016world-population-data-sheet.aspx 
reduce the 'unmet need for contraception' (women state preferences for fewer children than they achieve: McAllister et al. 2012) and how to improve the health of children and mothers. In either case, a better understanding of family dynamics, and how women make reproductive decisions may lead to better evidence-based policy.

Though the cooperative breeding hypothesis itself cannot be tested empirically, because in all populations women receive help of some kind in raising children, it is possible to test the corollary hypothesis that women who receive greater amounts of help are able to raise more children than those who receive less help. A more precise prediction is that the availability of helpful kin will be associated with higher fertility, because it reduces the costs of childbearing for women.

Here, I describe some of the results of a project aimed to test that prediction, and to further determine (1) whether positive associations between kin and fertility are plausibly driven by cooperation between kin; and (2) how associations between kin and fertility vary worldwide. Several previous studies have tested the association between the availability of kin and women's fertility. A review of this literature in 2011 found that, overall, there was some support for the hypothesis that kin availability is positively associated with fertility, though this was not universal: some studies showed either no association between kin and fertility, or even a negative association (Sear and Coall 2011). There were also variations in which kin were more likely to be associated with fertility. The availability of a woman's parents-in-law, for example, were more consistently positively associated with fertility than her parents. However, these studies were only able to demonstrate relatively crude associations between kin and fertility, as kin availability was typically measured either simply by survival status (whether a particular relative was alive or dead) or coresidence with women. Correlation doesn't necessarily imply causation, as there are potentially confounding factors which may drive this positive association. For example, kin share genes and environments, so that positive correlations between the survival status of kin and women's fertility may simply reflect a healthy family effect: families which have particularly fortunate genes or environments may both be able to live long lives and have high fertility. The project described here attempted to go beyond previous research to determine whether positive associations between kin and fertility are in fact driven by helping behaviour, as the cooperative breeding hypothesis predicts.

In addition, the project aimed to explore in more detail cross-cultural variation in associations between kin and fertility. While the prediction that kin will be positively associated with fertility is likely to hold across all populations, there may be some variability between populations in which kin help and what kind of help matters, because of the variability between populations in cultural factors, such as marriage and residence patterns, and in demographic factors such as fertility and mortality. All of these factors will affect which kin are available to women. Women may have more access to their husband's kin than their own relatives in patrilocal societies. In low mortality, low fertility societies, grandparents may be particularly important helpers throughout women's reproductive lives; whereas in higher fertility, higher mortality societies, grandparents may be more important early in women's reproductive careers, but older children may become important carers for later born children.

In this paper, I distinguish between 'high income' and 'lower income' populations, which divides human populations into contemporary populations with high levels of economic development, and also low mortality and fertility, such as those in Europe, North America and East Asia; and 'lower income' populations, which include all other contemporary nation-states, of lower and moderate levels of economic development, and also includes historical populations and small-scale societies studied by anthropologists, which are characterised by higher fertility and mortality. Clearly, this masks considerable variation within both categories; a more nuanced approach would be to explore how variation in factors such as income are associated with variation in kin influences on fertility, using the full spectrum of variation of income across different populations. In the absence of sufficient data to yet do this thoroughly, a first step is to explore whether a crude division of societies into high and lower income is helpful in understanding associations between kin and fertility. My reason for choosing this division is because income is an indicator of resource access, and resource access is likely to affect the mechanisms through which kin influence fertility.

In lower income contexts where resources are scarce and women may be malnourished, physiological mechanisms regulating fertility may 
be important in mediating relationships between kin and fertility: the help provided by kin may reduce the energetic burden of caring and providing for children, and allow women to conceive more easily (Kramer and Ellison 2010). In higher income populations, it is possible that the presence of helpful kin is less important, because all women have access to sufficient calories to reproduce, and also because women have access to formal institutions (such as paid childcare, or welfare and childcare/education provided by the state) which can potentially substitute for help from kin. However, we still expect that kin will matter even in high income populations: if our psychology has evolved to be sensitive to the presence or absence of helpful kin when making reproductive decisions, then kin availability may be important in the reproductive decision-making process, though may be mediated through psychological rather than physiological mechanisms (McAllister et al. 2016).

Kin presence may also influence fertility through routes other than support which reduces the costs of childbearing (in both high and lower income populations). Kin may provide social information or social pressures to have children (or not), or have them at a particular time, such as information about contraception or reproductive healthcare; or be a source of information about social norms surrounding reproduction (Moya and Sear, n.d.). For simplicity, we don't consider these potential mechanisms further (except briefly in section 6), both because they tend to be harder to measure than the provision of help, and also because they are likely to result in context-specific associations between kin and fertility (i.e. kin may promote fertility in some contexts but reduce fertility in others).

Note that the reproductive decision-making process is not necessarily assumed to be conscious in this framework: evolutionary hypotheses are typically agnostic about exactly how the decisionmaking process works; they simply predict which factors are likely to influence this process (Sear et al. 2016; Sear 2015). Nor does the cooperative breeding framework assume that kin are the only factor likely to influence fertility. Reproductive decisions are complex and influenced by many different factors, of which the availability of helpful kin will be just one. The focus is also on women's fertility because the majority of data on fertility relates to women, even though women do not make reproductive decisions in isolation.

\section{Kin and fertility in lower/ middle income contexts}

Much research investigating the cooperative breeding hypothesis has focused on lower and middle income contexts, often in small-scale, subsistence societies or historical datasets. These studies have consistently found that the presence of kin other than the mother improves child outcomes, particularly maternal grandmothers and older siblings of the child (Sear and Mace 2008; Bengtsson, Campbell, and Lee 2009; Dong et al. 2017) A related literature has demonstrated that grandmothers and older siblings do have important roles in childcare and supporting mothers in such populations, though the pathway from the presence of kin through the provision of childcare and other forms of help to higher child survival has not been directly tested (Meehan 2008; Meehan, Helfrecht, and Quinlan 2014; Meehan 2005; Gibson and Mace 2005; Kramer 2005; Weisner and Gallimore 1977; LeVine et al. 1996). In such contexts, it is therefore plausible that help from kin in raising children reduces the costs of childrearing for women, and so may result in higher fertility. Research testing whether the presence of kin increases female fertility has shown less consistently positive associations between kin and fertility in these populations, however (Sear and Coall 2011; Tsuya et al. 2010), and where positive associations have been demonstrated, whether there is a causal link between kin availability and fertility is still unclear.

Here I describe two studies conducted during my ERC project which were designed to test the cooperative breeding hypothesis more thoroughly, by investigating the proximate mechanisms through which kin may influence fertility (Snopkowski and Sear 2013; Snopkowski and Sear 2016). We focused particularly on the influence of parents and parentsin-law on a woman's fertility, partly because these are among the most likely helpers of women, but also for reasons of data availability. We analysed data from the 1987 Thailand Demographic and Health Survey (Snopkowski and Sear 2013), and the longitudinal Indonesia Family Life Survey (Snopkowski and Sear 2016); datasets chosen for their relatively detailed data on kin availability and cooperation between kin.

In Thailand, we found positive associations between the availability of kin and fertility, in that women who lived with their husband's kin had more births in total, achieved through shorter birth intervals and a higher likelihood of progressing from one birth 
to the next, than women who were not coresident with in-laws. Coresidence with her own kin did not have the same positive association with a woman's fertility, though there was some evidence that it did improve the health of her children. For this population, we didn't have data on direct helping between kin, but we did have data on a number of proximate determinants of fertility, that is, factors which are known to influence fertility, and were able to test whether husband's kin acted on fertility through the following pathways: women's labour force participation, both child and maternal health, women's age at marriage, contraceptive use, breastfeeding duration and desired fertility (Snopkowski and Sear 2013). Our analysis suggested that husband's kin do have direct influences on fertility, mediated through earlier age at marriage and delayed initiation of contraceptive use, and possibly shorter breastfeeding duration and decreased labour force participation, but not maternal or child health. This provides some evidence that kin influences on fertility are plausibly causal, since we were able to demonstrate not just crude associations between kin availability and fertility outcomes, but also that these associations are driven by associations between kin availability and several proximate determinants of fertility. But this analysis still doesn't tell us exactly how husband's kin may influence these proximate determinants of fertility, nor does it speak directly to the prediction that is it help from kin which increases women's fertility.

The longitudinal nature of the Indonesian dataset, and its very detailed information on intergenerational transfers, did allow us to test directly whether kin availability influences fertility through the provision of help (Snopkowski and Sear 2016). We had data on the geographic proximity of kin: not just whether they were alive or not, or coresident or not, but how far away they lived from their adult daughters and daughters-in-law. We also had data on contact frequency and helping behaviour between kin, in terms of financial resources and help around the house. We first confirmed that parents and parentsin-law do frequently provide help to adult children in this population, though parents tend to provide more help than parents-in-law. This help was not divided equally among all adult children, though, but directed towards those most in need of help, for example, those who had young children of their own; also, financial help was more often provided to adult children who were relatively poor; and household help was more likely to be provided to adult daughters who worked outside the home (Snopkowski and Sear 2015). This illustrates an important but under-appreciated point: the provision of help may be determined by the need of recipients. This may confound any analysis of the influence of kin on child or fertility outcomes, as it's possible that in some cases the receipt of high levels of help from kin may indicate poor condition on the part of recipients, instead of increased resources being available to the recipient which can then be directed towards increasing fertility or improving child outcomes.

We then demonstrated that help provided by the grandparental generation does mediate positive associations between kin availability and fertility. For all four types of kin - mothers, fathers, mothers-inlaw, fathers-in-law - we found that more help from each relative was associated with a higher probability of a subsequent birth, though these associations were stronger at lower parities (Snopkowski and Sear 2016). Our mediation analysis then demonstrated that positive relationships between measures of kin availability (i.e. geographic proximity) were only seen when kin provided help; again these relationships that were broadly observed for all four types of kin, though were strongest for mothers-in-law. This is an important result, as it is the first study, to our knowledge, to demonstrate empirical evidence that the association between kin and fertility is driven by the provision of help. This suggests that such associations cannot simply be dismissed as an artefact of shared genes or environment between kin.

\section{Kin and fertility in higher income populations}

Relatives clearly still help one another in higher income populations, but patterns of help show some differences, as well as similarities, compared to help in lower/middle income contexts. Grandparents are still important carers of grandchildren, given substantial evidence of their involvement with grandchildren (Coall and Hertwig 2010; Coall, Hilbrand, and Hertwig 2014; Glaser et al. 2013); and grandfathers may be relatively more important in providing grandparental investment in higher, versus lower, income contexts (Coall et al. 2016; Buchanan and Rotkirch 2016). There is less evidence that grandparental care improves child wellbeing in such populations, partly because there is less variation in clear cut measures of wellbeing such as health and survival, though there is some evidence that 
grandparental involvement improves psychological or cognitive outcomes (Coall and Hertwig 2011; Yorgason, Padilla-Walker, and Jackson 2011; Baydar and BrooksGunn 1991). Older siblings of children are no longer important, however, given low fertility rates and norms which have effectively extended childhood still further - children in high income populations are required to spend long periods in education, and are not considered competent in adult roles, including the care of younger children, until a relatively late age. Instead, mothers substitute in help from other individuals, notably formal sources of help, including paid childcare but also childcare, education, healthcare and other resources provided by the state.

Father involvement may also be relatively important, in at least some contexts in high income populations. Given small family sizes and geographical mobility, some women may have to rely particularly on help from partners in raising children, because of a relative lack of available kin. The importance of men's roles in the domestic sphere in affecting fertility decision-making has been emphasised in a number of recent papers, both empirical and theoretical (EspingAndersen and Billari 2015; Kan and Hertog 2017; Testa 2007). Rather than paternal involvement in childcare representing a new development in human history, however, this is likely more of a return to a more typical human pattern of sexual divisions of labour, with both women and men contributing both productive and reproductive labour. Simultaneously, however, some high income populations have relatively high rates of non-marital childbearing and divorce, so that many fathers live apart from their children, though may still invest substantially in their children. This too is not new in human history, given our demonstrable ability, across human history, to manage family relationships flexibly, and to make use of the help of extended family and unrelated individuals in childrearing.

Differences in the availability of help, as well as lower fertility, potentially make investigating kin influences on fertility more complicated in higher income populations. Low fertility may mean that kin help is less important, if kin help is primarily used to help support large family sizes. Women may also be able to compensate for a lack of kin support through formal means of support, making it harder to observe kin influences on fertility. Counter to these arguments is that formal forms of support may be (considered) less high quality than kin support. For example, paid childcare or formal education involves a high ratio of children to carers/educators, unlike kin care which may be one-on-one. Mothers and fathers may also have a greater need for advice and support from kin given that children are typically assumed to need very high levels of investment to thrive in high income populations, and that parents may have little experience with childcare before having children of their own. Further, our evolved psychology may still assume that supportive kin networks are vital for raising children successfully, so that we are reluctant to have children without such networks around us.

The empirical evidence on associations between kin and fertility in high income populations shows a mixed pattern of results (Schaffnit 2015). While several studies have found positive associations between kin and fertility, others found no relationships between these two variables, and a handful even found negative relationships between kin and fertility (Mathews and Sear 2009; Mathews and Sear 2013; Waynforth 2011; Kaptijn et al. 2010; Aassve, Meroni, and Pronzato 2012; Del Boca, Piazzalunga, and Pronzato 2014; Rindfuss et al. 2007; Kertzer et al. 2009; Balbo and Mills 2011). A problem with this literature is that the studies, at least those from Europe/US, are very diverse: a range of different fertility measures are used as the outcome variable (age at first birth, length of birth intervals, total number of children), different measures of kin support/availability are used (often geographic proximity or coresidence, but some studies used a variety of different measures of practical help or emotional support). Research on high income Asian populations found a more consistently positive influence of kin presence on fertility (Thornton et al. 1986; Tsay and Chu 2005; Chi and Hsin 1996; Fukukawa 2013; Nosaka 2009), perhaps because these studies were more uniform: typically measuring the impact of coresidence with parents-in-law on interbirth intervals (Schaffnit 2015).

Below, I briefly report on two analyses which examined kin influences on fertility in high income contexts, with the aim of providing a more detailed understanding of these relationships, in particular, whether these relationships differ for women in different socio-economic groups. High income populations are socioeconomically very diverse and often unequal. This heterogeneity needs to be taken into account given that we know that different SES strata differ both in their fertility behaviour and patterns of helping between kin (because of different levels of geographic mobility, for example: Nettle 2011), such that kin influences on fertility may differ between SES strata. 
The first analysis uses a large, multi-country dataset from Europe, in which we tested whether the availability of a woman's own parents is associated with three measures of fertility (Schaffnit and Sear 2014): age at first birth, total number of children and probability of childlessness (relatively high rates of non-marital childbearing mean data on a woman's in-laws is often less readily available in high income populations). Our analysis of Gender and Generations Programme (GGP) included data from 8 countries (Austria, Belgium, Bulgaria, France, Georgia, Lithuania, Norway, Russia), and although it allowed us to test for between-country differences in kin influences on fertility, we found (surprising) uniformity in our results across countries. We found some associations between kin and fertility, but these may be less clearly related to the provision of help than in the lower income contexts described above, since we were only able to use relatively crude indicators of parental availability. The death of the mother (but not father) was associated with a delayed first birth and a higher probability of childlessness, but not total number of children, suggesting that having a living mother positively influenced some aspects of fertility. In contrast, coresidence with parents reduces women's fertility: it delays first birth, increases the probability of childlessness and reduces the total number of children born. We suspect that coresidence with parents in the European context may be an indicator of the need for support on the part of the adult children, or alternatively an indication that the older generation need help from the younger generation, which would delay the younger generation's family formation. These relationships were particularly pronounced in women of lower socio-economic status, providing further evidence that coresidence may be an indicator of need in the European context.

Our second analysis, of Millennium Cohort Survey (MCS) data from the UK, allowed us to explore in greater detail patterns of helping behaviour between kin, and to test whether help was associated with the probability of having a second birth (a key indicator of overall fertility in such a low fertility context: Schaffnit and Sear 2017a). Before testing whether the provision of support was associated with the likelihood of second birth, we examined patterns of helping behaviour. We were particularly interested in the potential substitution of support: if support is necessary for women to reproduce (as predicted by the cooperative breeding hypothesis), then do women with a lack of one kind of support substitute in support from elsewhere (Harper and Ruicheva 2010)? Given the relative prominence of the nuclear family in the contemporary Western context, support is often provided by women's partners. In the MCS, we found that women without partners were, broadly, more likely to receive support from elsewhere: they were more likely to coreside with or receive financial support from their parents, more likely to report support from paid childcare sources and more likely to see friends often. These substitution effects were more pronounced among women in the lowest tercile of SES (who were much more likely to be unpartnered than those in the highest tercile); these women were also more likely to receive childcare from their parents if unpartnered (unlike the other SES terciles).

The MCS allowed us to conduct an unusually detailed analysis of whether several different types of support (childcare, financial support, emotional support) from different sources (partners, parents, parents-in-law, friends, formal sources of support such as paid childcare) were associated with fertility (see also: Tanskanen et al. 2014)). Our results suggest that, in the UK, who provides support matters less than the type of support provided. Broadly speaking, while emotional support (regardless of source) tends to be associated with higher likelihood of birth; financial support (from both parents and parentsin-law) is correlated with a reduced likelihood of birth (see also Schaffnit and Sear 2017b for a similar study which found different associations between emotional and financial support on fertility in the Netherlands). Results were roughly similar across SES groups, with the exception that childcare from kin increased the likelihood of progressing to second birth for lower, but not higher, income women (which may be because lower income women were more likely to receive childcare help from family than higher income women). This pattern of results may be explained because in high income populations the perception of support is more important in reproductive decisions than the provision of material support (perhaps with the exception of childcare). Further, direct financial transfers from family to women may be an indication of the need for extra support. Alternatively, or in addition, emotional measures of support may be more stable than material measures of support, if direct financial transfers fluctuate more over time, such that these emotional measures are better indicators of overall levels of support received by women during their reproductive lives. 


\section{Are kin always helpful?}

The cooperative breeding framework doesn't mean that all families will be models of harmonious cooperation. The need for cooperation between family members in raising children opens up the possibility of conflict within families (Sheppard and Sear 2016; Sear 2008; Strassmann and Garrard 2011; Mace 2013; Tomlin 1998; Ehrlich 2001). This may be conflict over the resources needed to raise children, and even competition over who within the family gets to reproduce. For example, models of intergenerational conflict have been developed to explain both why women stop having children relatively early in their lives (Cant and Johnstone 2008), and why first births may occur relatively late in women's lives (Moya and Sear 2014). Late in life women may give up reproductive opportunities in order to help younger women in their families have babies; this is the premise underlying the 'grandmother hypothesis' for the evolution of menopause, which has been proposed to explain why women universally stop reproducing by their late 40s, just half-way through their potential lifespan (Hawkes et al. 1998). While costs to the simultaneous reproduction of women and their mothers or mothersin-law have been shown (Lahdenperä et al. 2012; Sear, Mace, and McGregor 2000), attempts to determine whether reproductive conflict between generations influences variation in age at last birth, or menopause, in contemporary populations has so far received only limited support (Mace and Alvergne 2012; Snopkowski, Moya, and Sear 2014; Galbarczyk and Jasienska 2012), perhaps because menopause has largely solved the problem of intergenerational conflict over age at last birth, at a species level. There may be more scope for investigating whether age at first birth is influenced by intergenerational conflict over reproductive opportunities: early in their reproductive lives women may be helping the older generation of women raise children, leading to delayed first births in contexts where women are expected to help their mothers raise children (see next section).

In addition to competition within the family over who gets to reproduce, family members may come into conflict over reproduction because the interests of all family members are not perfectly aligned. For example, a persistent assumption in the literature is that men have desires for higher fertility than women, because they bear fewer costs of high fertility (Penn and Smith 2007; Greene and Biddlecom 2000). This has been proposed to explain why parents-in-law are more likely to be positively associated with fertility than a woman's own parents: parents-in-law are pronatal because they support and enforce the higher fertility desires of their sons, and are less concerned about the potential adverse health consequences of high rates of childbearing to women than are parents, because parents-in-law are not genetically related to their daughters-in-law (Sear, Mace, and McGregor 2003; Kadir et al. 2003). A theoretical modelling exercise, however, conducted as part of this ERC project, suggested that it is too simplistic to claim that differential costs of reproduction mean that men should have universally higher fertility preferences than women: men also suffer costs of reproduction, though these are different from the costs that women suffer; and the prevalence of monogamous marriage means that any costs of reproduction felt by wives will also impact their husband's reproductive success. So that the puzzles of why men do frequently (though not always) prefer larger family sizes than women, and why parents-in-law may be more pro-natal than parents, are still unexplained (Moya, Snopkowski, and Sear 2016). This example highlights one of the complications of investigating associations between kin and fertility: such associations may be influenced by factors other than helping between kin, such as social influence or conflict between relatives; mechanisms which require much greater investigation.

\section{Kin availability in childhood and age at first birth}

The analysis and literature discussed above all tackles the question of whether the availability of kin around the time that women are making reproductive decisions is associated with those decisions. But one of the most studied relationships in the literature is that between the presence or absence of parents in childhood and women's age at first birth: the absence of the father in childhood, in particular, has been frequently associated with earlier age at reproductive development for girls, including earlier age at menarche and first birth, at least in high income populations (Webster et al. 2014; Kiernan 1992; Quinlan 2003; Sheppard et al. 2014). The explanation for this given by evolutionary authors is that the lack of the father indicates a relatively harsh environment, where lifespans will be relatively short (Rickard, Frankenhuis, and Nettle 2014; Ellis 2004; Chisholm 1993; Belsky, Steinberg, and Draper 1991). 
This means that women should mature more quickly and have earlier first births, in order to make sure they have children before their (likely early) death. Other research confirms that harsh childhood environments, as measured by low socioeconomic status, are also associated with early first births (Nettle, Coall, and Dickins 2010). The sociologist Geronimus, taking a biosocial approach, explicitly brought kin into these arguments by suggesting one reason that girls in harsh environments should have earlier first births is to ensure that their mothers are still young and healthy enough to help them raise their children (Geronimus 1996).

Whether parental absence in childhood similarly affects age at first birth in lower/middle income contexts is less well studied. We have produced some work as part of this ERC project showing that father absence may also be associated with earlier first births in some lower/middle income contexts, but relationships in such contexts are much more variable than in high income populations (Moya et al., n.d.), and that father absence in childhood is not associated with earlier menarche as it seems to be in high income populations (Sheppard, Garcia, and Sear 2014; Sheppard, Snopkowski, and Sear 2014; see also Sohn 2017; Winking, Gurven, and Kaplan 2011). We suggested that an alternative (not necessarily mutually exclusive) hypothesis for why parental absence in childhood may be associated with earlier reproductive development is that it reflects an absence of intergenerational conflict (Moya and Sear 2014). Phrased differently, when parents are around, there is the potential for intergenerational conflict in childhood that parents may want their young adult children to stay at home and help raise younger siblings, rather than start having children themselves. Some evidence in support of this hypothesis has been found both in our own cross-cultural analysis of several low income populations (Moya et al., n.d.), and in a recent analysis of data from the UK (Smith 2017).

When considering the overall influence of kin on fertility, these associations need to be taken into account, not least because the direction of the association runs counter to the broad prediction from the cooperative breeding framework that kin availability should increase fertility. If (broadly speaking), the presence of kin in childhood delays first birth, but (broadly speaking) the presence of kin in adulthood speeds up progression to subsequent births, then is the overall influence of kin on fertility likely to be positive or negative? The (possibly unsatisfying) answer is likely to be: it depends on context. Context may affect the effect sizes of the relationships, the relative importance of age at first birth and interbirth intervals in determining overall fertility, and of course, kin influences themselves (which are variable between populations). So far, effect sizes have not been mentioned but, although many relationships between kin and fertility are statistically significant, effect sizes tend not to be large (at least in comparison to factors which do have substantial impacts on aspects of fertility, such as education). This means that, in high fertility societies, the overall influence of kin on fertility may be positive, if a small effect of family delaying age at first birth is overridden by small effects of family speeding up subsequent childbearing - simply because first births happen only once, whereas women may have several subsequent births. In low fertility societies, overall influences may be harder to predict: any influences on age at first birth may have limited effect on the total number of children born, since age at first birth is less strongly associated with total fertility than in high fertility contexts. Kin influences on subsequent fertility may be more important, though these influences may be more variable and context-specific than in high fertility populations.

\section{Conclusion}

Family matters, for fertility (and health) outcomes, though which family members matter depends on context. In low/middle income contexts, positive associations between the presence of kin and fertility are often observed, and are plausibly driven by the provision of help between family members. The picture is less clear-cut in high income contexts. While some positive associations between kin and fertility are seen, some negative associations are also observed, perhaps because some measures of family 'support' are in fact an indication of need on the part of the recipient, rather than an indication that the recipient has extra resources available which can be directed into childbearing. In high income contexts, different types of support appear to have different relationships with fertility: the provision of emotional support may be more important than material support, perhaps because material support can be provided by sources other than kin. Great care should be taken when measuring kin support, especially in 
high income contexts, since all support does not seem to be equal in terms of influencing fertility. Finally, heterogeneity within populations, particularly large, stratified societies, needs to be taken into account: in high income societies, particularly those with high levels of economic inequality, there may be variation in associations between kin and fertility, because of considerable heterogeneity in who provides women with support, with partners assuming importance for women who lack access to kin, but kin assuming more importance for those who lack access to partners.

In contemporary societies, of all levels of economic development, we have not 'lost our kin', since families remain important and common sources of support. The isolated nuclear family, male breadwinner-female homemaker model is therefore not a useful model of the family. Instead, a flexible model of the human family, with consistent support (though provided by a range of potential sources) from outside the parental relationship, as well as variable relationships between mothers and fathers, provides a much more accurate picture of how children are raised and reproductive decisions are made.

\section{Acknowledgements}

With enormous thanks to the European Research Council, who funded this work through a Starting Grant, StG-2010 263760-FAMMAT. This grant allowed me to work with Cristina Moya, Susie Schaffnit, Paula Sheppard and Kristin Snopkowski, without whom this paper would not be possible.

\section{References}

Aassve, Arnstein, Elena Meroni, and Chiara Pronzato. 2012. "Grandparenting and Childbearing in the Extended Family.” European Journal of Population / Revue Européenne de Démographie 28 (4): 499-518. doi:10.1007/ s10680-012-9273-2.

Aubel, J, I Toure, and M Diagne. 2004. "Senegalese Grandmothers Promote Improved Maternal and Child Nutrition Practices: The Guardians of Tradition Are Not Averse to Change.” Social Science \& Medicine 59 (5): 945-59.

Balbo, Nicoletta, and Melinda Mills. 2011. "The Influence of the Family Network on the Realisation of Fertility Intentions." Vienna Yearbook of Population Research 9. Vienna Institute of Demography (VID) of the Austrian Academy of Sciences in Vienna: 179-206.

Basu, Alaka. 2017. "When Women Becaome Good for Families, Did Families Become Bad for Women? Historical Changes in Women's Leisure as One Indicator of Their 'Status.”' In International Population Conference. Cape Town.

Baydar, Nazli, and Jeanne Brooks-Gunn. 1991. "Effects of Maternal Employment and Child-Care Arrangements on Preschoolers' Cognitive and Behavioral Outcomes: Evidence from the Children of the National Longitudinal Survey of Youth." Developmental Psychology 27 (6). American Psychological Association: 932-45. doi:10.1037/0012-1649.27.6.932.

Belsky, Jay, Laurence Steinberg, and Patricia Draper. 1991. "Childhood Experience, Interpersonal Development, and Reproductive Strategy: An Evolutionary Theory of Socialization." Child Development 62 (4): 647-70. doi:10.1111/j.1467-8624.1991.tb01558.x.

Bengtson, V L. 2001. "Beyond the Nuclear Family: The Increasing Importance of Multigenerational Bonds.” Journal of Marriage and the Family 63 (1): 1-16.

Bengtsson, Tommy, Cameron Campbell, and James Z Lee. 2009. Life under Pressure: Mortality and Living Standards in Europe and Asia, 1700-1900. MIT Press.

Bezner Kerr, Rachel, Laifolo Dakishoni, Lizzie Shumba, Rodgers Msachi, and Marko Chirwa. 2008. "'We Grandmothers Know Plenty': Breastfeeding, Complementary Feeding and the Multifaceted Role of Grandmothers in Malawi.” Social Science \& Medicine 66 (5): 1095-1105.

Buchanan, Ann, and Anna Rotkirch. 2016. Grandfathers: Global Perspectives. Palgrave Macmillan.

Burch, Thomas K, and Murray Gendell. 1970. "Extended Family Structure and Fertility: Some Conceptual and Methodological Issues." Journal of Marriage and Family 32 (2). National Council on Family Relations: 227-36.

Caldwell, J C. 1978. "A Theory of Fertility: From High Plateau to de-Stabilisation.” Population and Development Review 4 (4): 553-77.

Cant, Michael A, and Rufus A Johnstone. 2008. "Reproductive Conflict and the Separation of Reproductive Generations in Humans." Proceedings of the National Academy of Sciences 105 (14): 5332-36. doi:10.1073/pnas.0711911105.

Chi, P S K, and P L Hsin. 1996. "Family Structure and Fertility Behavior in Taiwan.” Population Research and Policy Review 15 (4): 327-39.

Chisholm, J S. 1993. "Death, Hope, and Sex: Life-History Theory and the Development of Reproductive Strategies." Current Anthropology 34 (1): 1-24.

Coall, David A, and R Hertwig. 2010. "Grandparental Investment: Past, Present and Future.” Behavioral and Brain Sciences 33 (1): 1-19.

Coall, David A, and Ralph Hertwig. 2011. "Grandparental Investment: A Relic of the Past or a Resource for the Future?” Current Directions in Psychological Science 20 (2). SAGE PublicationsSage CA: Los Angeles, CA: 93-98. doi:10.1177/0963721411403269.

Coall, David A, Sonja Hilbrand, and Ralph Hertwig. 2014. "Predictors of Grandparental Investment Decisions in Contemporary Europe: Biological Relatedness and Beyond.” PloS One 9 (1). Public Library of Science: e84082. doi:10.1371/journal.pone.0084082.

Coall, David A, Sonja Hilbrand, Rebecca Sear, and Ralph Hertwig. 2016. "A New Niche? The Theory of Grandfather Involvement.” In Grandfathers: Global Perspectives, 21-44. 
Coontz, Stephanie. 2004. "The World Historical Transformation of Marriage.” Journal of Marriage and Family 66 (4). Blackwell Publishing Ltd/Inc.: 974-79. doi:10.1111/j.00222445.2004.00067.x.

Crompton, Rosemary, Suzan Lewis, and Clare Lyonette. 2007. "Introduction: The Unravelling of the 'Male Breadwinner' Model - and Some of Its Consequences.” In Women, Men, Work and Family in Europe, edited by Rosemary Crompton, Suzan Lewis, and Clare Lyonette, 1-16. Palgrave Macmillan, London. doi:10.1007/978-0-230-80083-0_1.

Daly, M, and M Wilson. 1984. "A Sociobiological Analysis of Human Infanticide.” In Infanticide: Comparative and Evolutionary Perspectives, edited by G Hausfater and S B Hrdy, 487-502. New York: Aldine de Gruyter.

Del Boca, Daniela, Daniela Piazzalunga, and Chiara Pronzato. 2014. "Early Child Care and Child Outcomes: The Role of Grandparents.” IZA Discussion Paper No. 8565.

Dong, Hao, Matteo Manfredini, Satomi Kurosu, Wenshan Yang, and James Z. Lee. 2017. "Kin and Birth Order Effects on Male Child Mortality: Three East Asian Populations, 1716-1945." Evolution and Human Behavior 38 (2). Elsevier: 208-16. doi:10.1016/j.evolhumbehav.2016.10.001.

Douglass, Richard L, and Brenda F McGadney-Douglass. 2008. "The Role of Grandmothers and Older Women in the Survival of Children with Kwashiorkor in Urban Accra, Ghana.” Research in Human Development 5 (1): 26-43.

Dunifon, Rachel. 2013. "The Influence of Grandparents on the Lives of Children and Adolescents." Child Development Perspectives 7 (1): 55-60. doi:10.1111/cdep.12016.

Durette, Rob, Chandler Marrs, and Peter B Gray. 2011. "Fathers Faring Poorly: Results of an Internet-Based Survey of Fathers of Young Children." American Journal of Men's Health 5 (5): 395-401. doi:10.1177/1557988310378365.

Ehrlich, A S. 2001. "Power, Control and the Mother-in-Law Problem: Face-Offs in the American Nuclear Family.” In New Directions in Anthropological Kinship, edited by L Stone, 175-84. Oxford: Rowman and Littlefield.

Ellis, Bruce J. 2004. "Timing of Pubertal Maturation in Girls: An Integrated Life History Approach.” Psychological Bulletin 130 (6): 920-58.

Esping-Andersen, Gøsta, and Francesco C. Billari. 2015. "Re-Theorizing Family Demographics.” Population and Development Review 41 (1). Wiley-Blackwell: 1-31. doi:10.1111/j.1728-4457.2015.00024.x.

Flinn, M V. 1992. “Paternal Care in a Caribbean Village.” In Father-Child Relations: Cultural and Biosocial Contexts, edited by Hewlett. B.S., 57-84. New York: Aldine de Gruyter.

Fortunato, Laura. 2017. “Insights From Evolutionary Anthropology on the (Pre)history of the Nuclear Family." Cross-Cultural Research, February. SAGE PublicationsSage CA: Los Angeles, CA, 106939711769100. doi:10.1177/1069397117691006.

Fukukawa, Yasuyuki. 2013. "Grandparental Investment and Reproductive Success in Modern Japanese Society.” Journal of Evolutionary Psychology, April. Akadémiai Kiadó, co-published with Springer Science+Business Media B.V., Formerly Kluwer Academic Publishers B.V.

Galbarczyk, Andrzej, and Grazyna Jasienska. 2012. “Timing of Natural Menopause Covaries with Timing of Birth of a First
Daughter: Evidence for a Mother-daughter Evolutionary Contract?" HOMO - Journal of Comparative Human Biology 64 (3): 228-32.

Geronimus, A T. 1996. "What Teen Mothers Know.” Human Nature-an Interdisciplinary Biosocial Perspective 7 (4): 323-52.

Gettler, Lee T. 2016. “Becoming DADS: Considering the Role of Cultural Context and Developmental Plasticity for Paternal Socioendocrinology.” Current Anthropology 57 (S13). University of Chicago PressChicago, IL: S38-51. doi:10.1086/686149.

Gibson, M A, and R Mace. 2005. "Helpful Grandmothers in Rural Ethiopia: A Study of the Effect of Kin on Child Survival and Growth.” Evolution and Human Behavior 26 (6): 469-82.

Glaser, Karen, Debora Price, Giogio Di Gessa, Eloi Ribe, Rachel Stuchbury, and Anthea Tinker. 2013. "Grandparenting in Europe: Family Policy and Grandparents’ Role in Providing Childcare.” doi:ISBN 978-0-9573281-6-7.

Goody, J. 1976. Production and Reproduction. Cambridge: Cambridge University Press.

Gray, Peter B., and Eulynis Brown. 2015. "Fatherhood in St. Kitts: Patterns and Predictors of Partnership and Paternal Dynamics in a Caribbean Island.” Fathering: A Journal of Theory, Research, and Practice about Men as Fathers. doi:10.3149/fth.1301.18.

Gray, Peter B., and Alyssa N. Crittenden. 2014. "Father Darwin: Effects of Children on Men, Viewed from an Evolutionary Perspective.” Fathering 12 (2). Men's Studies Press: 121.

Greene, M E, and A E Biddlecom. 2000. "Absent and Problematic Men: Demographic Accounts of Male Reproductive Roles.” Population and Development Review 26 (1): 81-+.

Hahn-Holbrook, Jennifer, and Martie Haselton. 2014. "Is Postpartum Depression a Disease of Modern Civilization?” Current Directions in Psychological Science 23 (6). SAGE PublicationsSage CA: Los Angeles, CA: 395-400. doi:10.1177/0963721414547736.

Hakim, Catherine. 2003. "A New Approach to Explaining Fertility Patterns: Preference Theory." Population and Development Review 29 (3). Blackwell Publishing Ltd.: 349-74. doi:10.1111/j.1728-4457.2003.00349.x.

Hamilton, W D. 1964. "The Genetical Evolution of Social Behaviour I.” Journal of Theoretical Biology 7: 1-16.

Harknett, Kristen, and Caroline Sten Hartnett. 2014. "The Gap between Births Intended and Births Achieved in 22 European Countries, 2004-07." Population Studies 68 (3). Routledge: 265-82. doi:10.1080/00324728.2014.899612.

Harper, Sarah. 2000. Ageing Societies: Myths, Challenges and Opportunities. London: Routledge.

Harper, Sarah, and Iva Ruicheva. 2010. "Grandmothers as Replacement Parents and Partners: The Role of Grandmotherhood in Single Parent Families.” Journal of Intergenerational Relationships 8 (3). Taylor \& Francis Group : 219-33. doi:10.1080/15350770.2010.498779.

Hawkes, K, J F O’Connell, and N G Blurton Jones. 1989. "Hardworking Hadza Grandmothers.” In Comparative Socioecology: The Behavioural Ecology of Humans and Other Mammals, edited by V Standen and R A Foley, 341-66. Oxford: Blackwell. 
Hawkes, K, J F O’Connell, N G Blurton Jones, H Alvarez, and E L Charnov. 1998. "Grandmothering, Menopause and the Evolution of Human Life Histories.” Proceedings of the National Academy of Sciences, USA 95: 1336-39.

Hewlett, B S. 2000. "Culture, History and Sex: Anthropological Contributions to Conceptualizing Father Involvement." Marriage and Family Review 29 (2/3): 59-73.

Hilbrand, Sonja, David A Coall, Denis Gerstorf, and Ralph Hertwig. 2017. "Caregiving within and beyond the Family Is Associated with Lower Mortality for the Caregiver: A Prospective Study.” Evolution and Human Behavior 38 (3). Elsevier: 397-403. doi:10.1016/J. EVOLHUMBEHAV.2016.11.010.

Hilbrand, Sonja, David A Coall, Andrea H Meyer, Denis Gerstorf, and Ralph Hertwig. 2017. "A Prospective Study of Associations among Helping, Health, and Longevity." Social Science \& Medicine 187 (August). Pergamon: 109-17. doi:10.1016/J.SOCSCIMED.2017.06.035.

Hill, Kim, and Hillard Kaplan. 1999. "Life History Traits in Humans: Theory and Empirical Studies.” Annual Review of Anthropology 28: 397-430.

Hill, Kim, and A Magdalena Hurtado. 2009. "Cooperative Breeding in South American Hunter-Gatherers.” Proceedings of the Royal Society B: Biological Sciences 276 (1674): 3863-70. doi:10.1098/rspb.2009.1061.

Hill, Kim R, Robert S Walker, Miran Božičević, James Eder, Thomas Headland, Barry Hewlett, A Magdalena Hurtado, Frank Marlowe, Polly Wiessner, and Brian Wood. 2011. "Co-Residence Patterns in Hunter-Gatherer Societies Show Unique Human Social Structure.” Science 331 (6022): 1286-89. doi:10.1126/science.1199071.

Hrdy, Sarah Blaffer 2000a. Mother Nature: Maternal Instincts and the Shaping of the Species. London: Vintage.

---. 2000b. "The Optimal Number of Fathers: Evolution, Demography, and History in the Shaping of Female Mate Preferences." Annals of the New York Academy of Sciences 907: 75-96.

---. 2005. "Cooperative Breeders with an Ace in the Hole." In Grandmotherhood: The Evolutionary Significance of the Second Half of Female Life, edited by E Voland, A Chasiotis, and W Schiefenhoevel, 295-317. New Brunswick: Rutgers University Press.

---. 2008. "Cooperative Breeding and the Paradox of Facultative Fathering ." In Neurobiology of the Parental Brain, edited by R S Bridges, 407-16. New York: Academic Press.

---. 2009. Mothers and Others: The Evolutionary Origins of Mutual Understanding. Cambridge, Massachusetts: Belknap Press.

---. 2016. "Variable Postpartum Responsiveness among Humans and Other Primates with 'cooperative Breeding': A Comparative and Evolutionary Perspective.” Hormones and Behavior 77 (January): 272-83. doi:10.1016/j. yhbeh.2015.10.016.

Hrdy, Sarah Blaffer, and Daniela F Sieff. 2015. "The Natural History of Mothers and Infants: An Evolutionary and Anthropological Perspective.” In Understanding and Healing Emotional Trauma, edited by Daniela F Sieff, 182-202. UK: Routledge.
Ivey, P K. 2000. "Cooperative Reproduction in Ituri Forest Hunter-Gatherers: Who Cares for Efe Infants." Current Anthropology 41 (5): 856-66.

Kadir, M M, F F Fikree, A Khan, and F Sajan. 2003. "Do Mothers-in-Law Matter? Family Dynamics and Fertility Decision-Making in Urban Squatter Settlements of Karachi, Pakistan.” Journal of Biosocial Science 35 (4): 545-58.

Kan, Man-Yee, and Ekaterina Hertog. 2017. “Domestic Division of Labour and Fertility Preference in China, Japan, South Korea, and Taiwan.” Demographic Research 36 (February): 557-88. doi:10.4054/DemRes.2017.36.18.

Kanji, Shireen. 2017. "Grandparent Care: A Key Factor in Mothers' Labour Force Participation in the UK.” Journal of Social Policy, November. Cambridge University Press, 1-20. doi:10.1017/S004727941700071X.

Kaplan, Hillard, and Jane Lancaster. 2003. “An Evolutionary and Ecological Analysis of Human Fertility, Mating Patterns and Parental Investment." In Offspring: Human Fertility in Biodemographic Perspective, edited by $\mathrm{K} \mathrm{W}$ Wachter and R A Bulatao, 170-223. Washington: National Academies Press.

Kaplan, Hillard S, Paul L Hooper, and Michael Gurven. 2009. "The Evolutionary and Ecological Roots of Human Social Organization." Philosophical Transactions of the Royal Society B: Biological Sciences 364 (1533): 3289-99. doi:10.1098/rstb.2009.0115.

Kaptijn, Ralf, Fleur Thomese, Theo G van Tilburg, and Aart C Liefbroer. 2010. "How Grandparents Matter: Support for the Cooperative Breeding Hypothesis in a Contemporary Dutch Population." Human Nature (Hawthorne, N.Y.) 21 (4): 393-405. doi:10.1007/s12110-010-9098-9.

Kertzer, David I, Michael J White, Laura Bernardi, and Giuseppe Gabrielli. 2009. "Italy's Path to Very Low Fertility: The Adequacy of Economic and Second Demographic Transition Theories.” European Journal of Population 25 (1): 89-115. doi:10.1007/s10680-008-9159-5.

Kiernan, Kathleen E. 1992. "The Impact of Family Disruption in Childhood on Transitions Made in Young Adult Life.” Population Studies 46 (2): 213-34.

Kramer, K L. 2005. "Children's Help and the Pace of Reproduction: Cooperative Breeding in Humans." Evolutionary Anthropology 14 (6): 224-37.

Kramer, K L, and P T Ellison. 2010. "Pooled Energy Budgets: Resituating Human Energy -Allocation Trade-Offs.” Evolutionary Anthropology: Issues, News, and Reviews 19 (4). Wiley Subscription Services, Inc., A Wiley Company: 136-47. doi:10.1002/evan.20265.

Lahdenperä, Mirkka, Duncan OS Gillespie, Virpi Lummaa, and Andrew F Russell. 2012. "Severe Intergenerational Reproductive Conflict and the Evolution of Menopause." Ecology Letters 15 (11): 1283-90.

Laslett, Peter. 1988. "Family, Kinship and Collectivity as Systems of Support in Pre-Industrial Europe: A Consideration of the 'nuclear-Hardship' Hypothesis.” Continuity and Change 3 (2). Cambridge University Press: 153. doi:10.1017/S026841600000093X.

LeVine, R A, S Dixon, S LeVine, A Richman, P H Leiderman, C H Keefer, and T B Brazelton. 1996. Childcare and Culture: 
Lessons from Africa. Cambridge: Cambridge University Press.

LeVine, R A 2014. "Attachment Theory as Cultural Ideology." In Different Faces of Attachment: Cultural Variations on a Universal Human Need, 50-65.

Mace, Ruth. 2013. "Cooperation and Conflict between Women in the Family.” Evolutionary Anthropology: Issues, News, and Reviews 22 (5): 251-58. doi:10.1002/evan.21374.

Mace, Ruth, and Alexandra Alvergne. 2012. "Female Reproductive Competition within Families in Rural Gambia.” Proceedings. Biological Sciences 279 (1736). The Royal Society: 2219-27. doi:10.1098/rspb.2011.2424.

Mace, Ruth, and Rebecca Sear. 2005. “Are Humans Cooperative Breeders?” In Grandmotherhood: The Evolutionary Significance of the Second Half of Female Life, edited by E Voland, A Chasiotis, and W Schiefenhoevel, 143-59. New Brunswick: Rutgers University Press.

Mathews, Paul S, and Rebecca Sear. 2009. "Family and Fertility: Kin Influence on the Probability of First Birth.” British Society for Population Studies Conference. Brighton, UK.

Mathews, Paul S, and Rebecca Sear. 2013. "Family and Fertility: Kin Influence on the Progression to a Second Birth in the British Household Panel Study." PloS One 8 (3). Public Library of Science: e56941. doi:10.1371/journal. pone.0056941.

Mattison, Siobhán M., Brooke Scelza, and Tami Blumenfield. 2014. "Paternal Investment and the Positive Effects of Fathers among the Matrilineal Mosuo of Southwest China." American Anthropologist 116 (3): 591-610. doi:10.1111/aman.12125.

McAllister, Lisa, Michael Gurven, Hillard Kaplan, and Jonathan Stieglitz. 2012. "Why Do Women Have More Children than They Want? Understanding Differences in Women's Ideal and Actual Family Size in a Natural Fertility Population.” American Journal of Human Biology 24 (6). Wiley Subscription Services, Inc., A Wiley Company: 786-99. doi:10.1002/ajhb.22316.

McAllister, Lisa, Gillian Pepper, Sandra Virgo, and David A Coall. 2016. "The Evolved Psychological Mechanisms of Fertility Motivation: Hunting for Causation in a Sea of Correlation." Philosophical Transactions of the Royal Society B, Biological Sciences.

Meehan, Courtney L 2005. “The Effects of Residential Locality on Parental and Alloparental Investment among the Aka Foragers of the Central African Republic." Human Nature 16 (1): 58-80.

---. 2008. "Allomaternal Investment and Relational Uncertainty among Ngandu Farmers of the Central African Republic." Human Nature 19 (2): 211-26. doi:10.1007/ s12110-008-9039-z.

Meehan, Courtney L, Courtney Helfrecht, and Robert J Quinlan. 2014. “Cooperative Breeding and Aka Children's Nutritional Status: Is Flexibility Key?” American Journal of Physical Anthropology 153 (4): 513-25. doi:10.1002/ ajpa.22415.

Moya, Cristina, Monique Borgerhoff Mulder, Heidi Colleran, Drew Gerkey, Mhairi A. Gibson, Michael Gurven, Joseph Henrich, et al. n.d. "Intergenerational Conflict May Explain Why Parents Delay the Onset of Their Children's Reproduction: A Cross-Cultural Analysis.”
Moya, Cristina, and Rebecca Sear. n.d. "Family Matters, but How? A Theoretical Framework for Parsing Mechanisms of Kin Influence on Reproductive Outcomes.”

---. 2014. "Intergenerational Conflicts May Help Explain Parental Absence Effects on Reproductive Timing: A Model of Age at First Birth in Humans.” PeerJ 2 (January). PeerJ Inc.: e512. doi:10.7717/peerj.512.

Moya, Cristina, Kristin Snopkowski, and Rebecca Sear. 2016. "What Do Men Want? Re-Examining Whether Men Really Benefit from Higher Fertility than Is Optimal for Women.” Philosophical Transactions of the Royal Society B, Biological Sciences 371 (1692): 20150149.

Myers, Sarah, Oskar Burger, and Sarah E. Johns. 2016. "Postnatal Depression and Reproductive Success in Modern, Low-Fertility Contexts.” Evolution, Medicine, and Public Health 2016 (1). Oxford University Press: 71-84. doi:10.1093/emph/eow003.

Nettle, Daniel. 2011. "Flexibility in Reproductive Timing in Human Females: Integrating Ultimate and Proximate Explanations." Philosophical Transactions of the Royal Society B: Biological Sciences 366 (1563): 357-65.

Nettle, Daniel, David A Coall, and Thomas E Dickins. 2010. "Early-Life Conditions and Age at First Pregnancy in British Women.” Proceedings of the Royal Society B: Biological Sciences. doi:10.1098/rspb.2010.1726.

Newson, L, T Postmes, S E G Lea, and P Webley. 2005. "Why Are Modern Families Small? Toward an Evolutionary and Cultural Explanation for the Demographic Transition." Personality and Social Psychology Review 9 (4): 360-75.

Nosaka, Akiko. 2009. “The M-Shaped Dilemma: Life Strategies and Fertility Trends among Working Women in Contemporary Japan.” Ethnology: An International Journal of Cultural and Social Anthropology.

Otto, Hiltrud, and Heidi Keller. 2014. Different Faces of Attachment: Cultural Variations on a Universal Human Need. Cambridge University Press.

Penn, Dustin J, and Ken R Smith. 2007. "Differential Fitness Costs of Reproduction between the Sexes.” PNAS 104 (2): 553-58. doi:10.1073/pnas.0609301103.

Popenoe, David. 1993. “American Family Decline, 1960-1990: A Review and Appraisal." Journal of Marriage and the Family 55 (3): 527. doi:10.2307/353333.

Quinlan, R J. 2003. "Father Absence, Parental Care, and Female Reproductive Development.” Evolution and Human Behavior 24 (6): 376-90.

Reiches, M, P T Ellison, S Lipson, K Sharrock, E Gardiner, and L G Duncan. 2009. "Pooled Energy Budget and Human Evolution.” American Journal of Human Biology.

Rickard, Ian J., Willem E. Frankenhuis, and Daniel Nettle. 2014. "Why Are Childhood Family Factors Associated With Timing of Maturation? A Role for Internal Prediction.” Perspectives on Psychological Science 9 (1). SAGE PublicationsSage CA: Los Angeles, CA: 3-15. doi:10.1177/1745691613513467.

Rindfuss, Ronald R., David K. Guilkey, S. Philip. Morgan, Øystein. Kravdal, and Karen Benjamin. Guzzo. 2007. "Child Care Availability and First-Birth Timing in Norway." Demography 44 (2): 345-72. doi:10.1353/dem.2007.0017.

Ruggles, Steven. 1986. "Availability of Kin and the Demography of Historical Family Structure.” Historical Methods: A 
Journal of Quantitative and Interdisciplinary History 19 (3). Taylor \& Francis Group : 93-102. doi:10.1080/01615440.198 6.9955249 .

---. 2010. "Stem Families and Joint Families in Comparative Historical Perspective." Population and Development Review 36 (3). NIH Public Access: 563-77.

Scelza, Brooke A, and Joan B Silk. 2014. "Fosterage as a System of Dispersed Cooperative Breeding: Evidence from the Himba." Human Nature (Hawthorne, N.Y.) 25 (4): 448-64. doi:10.1007/s12110-014-9211-6.

Schaffnit, Susan B, and Rebecca Sear. 2014. "Wealth Modifies Relationships between Kin and Women's Fertility in High-Income Countries.” Behavioral Ecology 25 (4): 834-42. doi:10.1093/beheco/aru059.

---. 2017a. "Support for New Mothers and Fertility in the United Kingdom: Not All Support Is Equal in the Decision to Have a Second Child.” Population Studies 71 (3): 345-61.

--_. 2017b. "Supportive Families versus Support from Families: The Decision to Have a Child in the Netherlands.” Demographic Research2 37 (4): 414-54.

Sear, Rebecca. 2008. "Kin and Child Survival in Rural Malawi - Are Matrilineal Kin Always Beneficial in a Matrilineal Society?" Human Nature-an Interdisciplinary Biosocial Perspective 19 (3): 277-93. doi:10.1007/s12110-008-9042-4.

---. 2015. "Evolutionary Contributions to the Study of Human Fertility.” Population Studies 69 Suppl 1 (April). Routledge: S39-55. doi:10.1080/00324728.2014.982905.

---. 2016. "Beyond the Nuclear Family: An Evolutionary Perspective on Parenting.” Current Opinion in Psychology 7 (August): 98-103. doi:10.1016/j.copsyc.2015.08.013.

Sear, Rebecca, and David A Coall. 2011. "How Much Does Family Matter? Cooperative Breeding and the Demographic Transition.” Population and Development Review 37 (Supplement s1): 81-112.

Sear, Rebecca, David W Lawson, Hillard Kaplan, and Mary K Shenk. 2016. "Understanding Variation in Human Fertility: What Can We Learn from Evolutionary Demography?" Philosophical Transactions of the Royal Society of London. Series B, Biological Sciences 371 (1692). The Royal Society: 206-64. doi:10.1098/rstb.2015.0144.

Sear, Rebecca, and Ruth Mace. 2008. "Who Keeps Children Alive? A Review of the Effects of Kin on Child Survival." Evolution and Human Behavior 29 (1): 1-18.

Sear, Rebecca, Ruth Mace, and Ian A McGregor. 2000. "Maternal Grandmothers Improve the Nutritional Status and Survival of Children in Rural Gambia.” Proceedings of the Royal Society of London, Series B, Biological Sciences 267: 461-67.

---. 2003. "The Effects of Kin on Female Fertility in Rural Gambia." Evolution and Human Behavior 24: 25-42.

Shenk, Mary K., and Siobhán M. Mattison. 2011. "The Rebirth of Kinship.” Human Nature 22 (1-2). Springer US: 1-15. doi:10.1007/s12110-011-9105-9.

Sheppard, Paula, Justin R Garcia, and Rebecca Sear. 2014. "A Not-so-Grim Tale: How Childhood Family Structure Influences Reproductive and Risk-Taking Outcomes in a Historical U.S. Population.” PloS One 9 (3). Public Library of Science: e89539. doi:10.1371/journal.pone.0089539.

Sheppard, Paula, Susan B Schaffnit, Justin R Garcia, and Rebecca Sear. 2014. "Fostering Relations: First Sex and Marital Timings for Children Raised by Kin and Non-Kin
Carers." Evolution and Human Behavior 35 (3): 161-68. doi:10.1016/j.evolhumbehav.2013.12.002.

Sheppard, Paula, and Rebecca Sear. 2016. "Do Grandparents Compete with or Support Their Grandchildren? In Guatemala, Paternal Grandmothers May Compete, and Maternal Grandmothers May Cooperate.” Royal Society Open Science 3 (4).

Sheppard, Paula, Kristin Snopkowski, and Rebecca Sear. 2014. "Father Absence and Reproduction-Related Outcomes in Malaysia, a Transitional Fertility Population." Human Nature (Hawthorne, N.Y.) 25 (2): 213-34. doi:10.1007/s12110014-9195-2.

Silverstein, Louise B., Carl F. Auerbach, and Ronald F. Levant. 2002. "Contemporary Fathers Reconstructing Masculinity: Clinical Implications of Gender Role Strain.” Professional Psychology: Research and Practice 33 (4): 361-69. doi:10.1037/0735-7028.33.4.361.

Smith, Daniel. 2017. "O Brother, Where Art Thou? Investment in Siblings for Inclusive Fitness Benefits, Not Father Absence, Predicts Earlier Age at Menarche.” Biology Letters 13 (10). The Royal Society: 20170464. doi:10.1098/rsbl.2017.0464.

Snopkowski, Kristin, Cristina Moya, and Rebecca Sear. 2014. "A Test of the Intergenerational Conflict Model in Indonesia Shows No Evidence of Earlier Menopause in FemaleDispersing Groups.” Proceedings. Biological Sciences / The Royal Society 281 (1788): 20140580. doi:10.1098/ rspb.2014.0580.

Snopkowski, Kristin, and Rebecca Sear. 2013. "Kin Influences on Fertility in Thailand: Effects and Mechanisms." Evolution and Human Behavior 34 (2): 130-38. doi:10.1016/j. evolhumbehav.2012.11.004.

---. 2015. “Grandparental Help in Indonesia Is Directed Preferentially towards Needier Descendants: A Potential Confounder When Exploring Grandparental Influences on Child Health.” Social Science \& Medicine (1982) 128 (March): 105-14. doi:10.1016/j.socscimed.2015.01.012.

--_. 2016. "Does Grandparental Help Mediate the Relationship between Kin Presence and Fertility?” Demographic Research 34 (17).

Sohn, Kitae. 2017. "The Null Relation between Father Absence and Earlier Menarche.” Human Nature 28 (4). Springer US: 407-22. doi:10.1007/s12110-017-9299-6.

Strassmann, Beverly, and Wendy Garrard. 2011. "Alternatives to the Grandmother Hypothesis: A Meta-Analysis of the Association between Grandparental and Grandchild Survival in Patrilineal Populations." Human Nature 22 (1). Springer New York: 201-22. doi:10.1007/s12110-011-9114-8.

Tanskanen, Antti O., Markus Jokela, Mirkka Danielsbacka, and Anna Rotkirch. 2014. "Grandparental Effects on Fertility Vary by Lineage in the United Kingdom." Human Nature 25 (2). Springer US: 269-84. doi:10.1007/s12110-014-9200-9.

Testa, Maria Rita. 2007. "Childbearing Preferences and Family Issues in Europe: Evidence from the Eurobarometer 2006 Survey." Vienna Yearbook of Population Research 5 (1). Vienna Institute of Demography (VID) of the Austrian Academy of Sciences in Vienna: 357-79.

Thornton, Arland, Freedman Ronald, Sun Te-Hsiung, and Chang Ming-Cheng. 1986. "Intergenerational Relations and Reproductive Behavior in Taiwan.” Demography 23 (2). Population Association of America: 185-97. 
Tomlin, Angela. 1998. “Grandparents' Influences on Grandchildren.” In Handbook on Grandparenthood, 159-70. Greenwood Press.

Tsay, Wen-Jen, and C Y Cyrus Chu. 2005. “The Pattern of Birth Spacing during Taiwan's Demographic Transition.” Journal of Population Economics 18 (2): 323-36.

Tsuya, Noriko O, Feng Wang, George Alter, and James Z Lee. 2010. Prudence and Pressure: Reproduction and Human Agency in Europe and Asia, 1700-1900. MIT Press.

Turke, P W. 1989. "Evolution and the Demand for Children." Population and Development Review 15: 61-90.

Vicedo, Marga. 2013. The Nature and Nurture of Love: From Imprinting to Attachment in Cold War America. Chicago: University of Chicago Press.

Walker, Robert S, Kim R Hill, Mark V Flinn, and Ryan M Ellsworth. 2011. "Evolutionary History of Hunter-Gatherer Marriage Practices.” PLoS ONE 6 (4). Public Library of Science: e19066.

Waynforth, D. 2011. “Grandparental Investment and Reproductive Decisions in the Longitudinal 1970 British Cohort Study.” Proceedings of the Royal Society B: Biological Sciences 279 (1731): 1155-60. doi:10.1098/ rspb.2011.1424.
Webster, G. D., J. A. Graber, A. N. Gesselman, B. S. Crosier, and T. O. Schember. 2014. "A Life History Theory of Father Absence and Menarche: A Meta-Analysis.” Evolutionary Psychology 12 (2). SAGE Publications: 147470491401200200. doi:10.1177/147470491401200202.

Weisner, T S, and R Gallimore. 1977. "My Brother's Keeper: Child and Sibling Caretaking.” Current Anthropology 18 (2): 169-90.

Winking, Jeffrey, Michael Gurven, and Hillard Kaplan. 2011. "Father Death and Adult Success among the Tsimane: Implications for Marriage and Divorce." Evolution and Human Behavior 32 (2): 79-89. doi:DOI: 10.1016/j. evolhumbehav.2010.08.002.

Wisner, Katherine L., Christina Chambers, and Dorothy K. Y. Sit. 2006. "Postpartum Depression: A Major Public Health Problem.” JAMA 296 (21). American Medical Association: 2616. doi:10.1001/jama.296.21.2616.

Yorgason, Jeremy B., Laura Padilla-Walker, and Jami Jackson. 2011. "Nonresidential Grandparents' Emotional and Financial Involvement in Relation to Early Adolescent Grandchild Outcomes." Journal of Research on Adolescence 21 (3). Blackwell Publishing Inc: 552-58. doi:10.1111/j.15327795.2010.00735.x. 